\title{
Film persistency of new high-temperature water-based batch corrosion inhibitors for oil and gas wells
}

\author{
Sunder Ramachandran • Carlos Menendez • \\ Vladimir Jovancicevic $\cdot$ Jeff Long
}

Received: 12 January 2011/ Accepted: 7 July 2012 / Published online: 30 August 2012

(C) The Author(s) 2012. This article is published with open access at Springerlink.com

\begin{abstract}
Water-based corrosion inhibitors, in addition to providing improved performance, offer several other advantages over oil-based corrosion inhibitors, such as better water-partitioning characteristics, high flash points, and higher reportable quantities if a spill occurs. We have found in several instances that new water-based corrosion inhibitor products provide longer treatment lives and better protection than similar inhibitors in oil-based formulations. Corrosion inhibition in high-temperature (HT) oil and gas wells has been frequently accomplished using oil-based corrosion inhibitors. This paper presents some earlier laboratory work and field performance data on new waterbased corrosion inhibitors relative to conventional oilbased HT corrosion inhibitors. A laboratory investigation using white light interferometry is also presented on the film thickness and uniformity measurements of corrosion inhibitor films. This information is compared with field performance of the corrosion inhibitor.
\end{abstract}

Keywords High temperature - Corrosion inhibition . Batch treatment $\cdot$ Film persistency $\cdot \mathrm{CO}_{2}$ corrosion

\section{Introduction}

Nickel-based alloys often become difficult to use in ultra high-pressure and high-temperature (HT) wells. It can take

S. Ramachandran $(\bowtie) \cdot C$. Menendez $\cdot$ V. Jovancicevic

Baker Hughes, 12645 West Airport Blvd.,

Sugar Land, TX 77478, USA

e-mail: Sunder.Ramachandran@bakerhughes.com

J. Long

Baker Hughes, 2101 Market Street, Building B,

Midland, TX 79703-7510, USA over a year to obtain nickel-based alloy tubing and casing strings from the manufacturer (Zeringue 2006). Nickelbased alloys are also susceptible to stress-crack corrosion in the presence of hydrogen sulfide.

Carbon steel, in conjunction with corrosion inhibitors, has been used in several wells above $300{ }^{\circ} \mathrm{F}\left(150{ }^{\circ} \mathrm{C}\right)$ (Goodfellow and Barr 2001; Place 1992; Smith 1982; Ramachandran et al. 2006). Oil-soluble corrosion inhibitors have been developed and used in HT gas wells. In previous work (Ramachandran et al. 2006), we have documented the performance of oil-soluble corrosion inhibitors in extremely challenging laboratory corrosion tests. The performance of HT oil-soluble corrosion inhibitors in field situations with high bottom hole temperatures, high partial pressures of carbon dioxide, and some hydrogen sulfide and brines of different salinities has also been documented in this work (Ramachandran et al. 2006). Corrosion inhibitors that work in these systems often have large alkyl tail groups that help bind the monolayer or bi-layer film on the surface (Ramachandran et al. 1996; Jovancicevic et al. 1998; Ramachandran and Jovancicevic 1998).

Methods have been developed to formulate organic molecules with large alkyl tails in water-based products (Yang and Jovancicevic 2009). We have found in several instances that new water-based corrosion inhibitor products provide longer treatment lives and better protection than similar inhibitors in oil-based formulations (Yang et al. 2007). A new water-dispersible, HT corrosion inhibitor was developed that had similar HT stability and corrosion inhibitor properties as a successful oil-soluble corrosion inhibitor (Ramachandran et al. 2009).

Optical profiling (White Light Profilometry) is a technique used to determine the three-dimensional profile of objects in a non-invasive manner. The method has been 
extended to measure the thickness of semi-transparent batch inhibitor films (Menendez et al. 2010).

This paper provides information that compares the laboratory and field performance of water-based corrosion inhibition treatment with oil-based corrosion inhibitor performance. The new corrosion inhibitor highlighted can provide corrosion protection at temperatures as high as $400{ }^{\circ} \mathrm{F}\left(204^{\circ} \mathrm{C}\right)$. The paper also uses optical profiling to compare the film thickness and uniformity of oil-based and water-based corrosion inhibitors obtained under simulated field conditions.

\section{Experimental}

The film persistency of corrosion inhibitors was tested using the wheel bomb (WB) apparatus (Ramachandran et al. 2009). C1018 carbon steel coupons were initially weighed. The coupons were then filmed with corrosion inhibitor at different concentration of inhibitors in soda bottles under saturated $\mathrm{CO}_{2}$ and $180^{\circ} \mathrm{F}\left(82{ }^{\circ} \mathrm{C}\right)$ conditions for $1 \mathrm{~h}$. In this test, filming occurs from dispersed solution of concentrated corrosion inhibitor in a brine solution. The coupons were then rinsed with de-ionized water and transferred to the WB in inhibitor-free brine/oil mixture. The tests were performed at $350{ }^{\circ} \mathrm{F}\left(177^{\circ} \mathrm{C}\right)$. The tests were performed with $\mathrm{CO}_{2}$ at a pressure of $100 \mathrm{psi}(687 \mathrm{kPa})$. The composition of brine used in the test is shown in Table 1.

The brine/oil ratio was $90 / 10$ in these tests. The hydrocarbon used in the tests was an aliphatic hydrocarbon solvent (Isopar M). The test was run for $18 \mathrm{~h}$. At the end of the test, the coupons were wiped clean, briefly immersed in inhibited acid solution and then weighed. The corrosion rate was measured using weight loss.

The WB test is also used to test the ability of coupons filmed in neat corrosion inhibitor solutions to prevent corrosion. In these tests, the coupon was filmed in neat inhibitor for $1 \mathrm{~h}$ under a $\mathrm{CO}_{2}$ atmosphere at appropriate conditions. The coupons were rinsed with DI water and tested. In one WB test, the brine shown in Table 1 is used. The test was performed at room temperature $77^{\circ} \mathrm{F}\left(25^{\circ} \mathrm{C}\right)$ and with 15 psi $\mathrm{CO}_{2}(104 \mathrm{kPa})$. Another WB test was performed under the condition of the pressurized WB test in a published work (Yang et al. 2007).

Table 1 Composition of brine used in film persistency WB test

\begin{tabular}{lc}
\hline Component & Concentration $(\mathrm{mg} / \mathrm{l})$ \\
\hline $\mathrm{CaCl}_{2} \cdot 2 \mathrm{H}_{2} \mathrm{O}$ & 2,190 \\
$\mathrm{MgCl}_{2} \cdot 6 \mathrm{H}_{2} \mathrm{O}$ & 580 \\
$\mathrm{NaHCO}_{3}$ & 330 \\
$\mathrm{NaCl}$ & 15,390 \\
\hline
\end{tabular}

The analysis of the film thickness was achieved using techniques similar to those published previously (Menendez et al. 2010). A WYKO ${ }^{\mathrm{TM}}$ NT9100 optical profiler (WLI) was equipped with various objectives, and an automated stage was employed in this study. Interference in WLI is used to determine when a point on the sample is in exact focus, as the instrument is adjusted to give maximum constructive interference at best focus. By scanning the lens towards the surface, the height of all pixels in the image can be determined with high precision, provided that enough light is reflected back into the lens from that point. This technique has a depth resolution of $3 \mathrm{~nm}$. The authors (Menendez et al. 2010) describe the software needed to analyze a thick film. This option is used in this work. The thick film code is used to measure the thickness of the transparent film at each point of the film laid over the sample. The detection limit of this method is $\sim 2 \mu \mathrm{m}$. In Fig. 1, a schematic diagram of the film thickness measurement technique is shown.

Film thickness measurement requires calibration because light travels through a film that features a refraction index different from air. To conduct the calibration, a portion of the surface is imaged, which leaves an area without film to create a step to the bare substrate (see Fig. 2). A thick film measurement is performed where single envelope data are set to surface 2 (inhibitor/metal interface). 2D cursors are used later to examine the film-tono-film interface. The value of the refraction index of inhibitor film is adjusted until the substrate appears continuous across the film boundary.

The images shown in Fig. 3 serve as examples of the two sets of fringes that are detected as the instrument runs through focus on top of the film and on the film-metal interface. The thick film analysis tool provides images for the top of the film and the surface of the steel substrate.

An image (i.e., film thickness) obtained by subtracting the two images is also provided. The image provided for the top of the film (film surface views) was used to describe such film features as uniformity and continuity. In areas

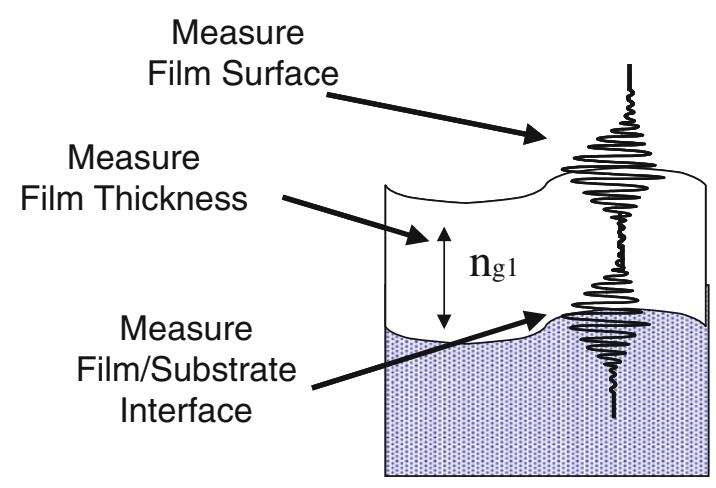

Fig. 1 Schematic of a film thickness measurement 


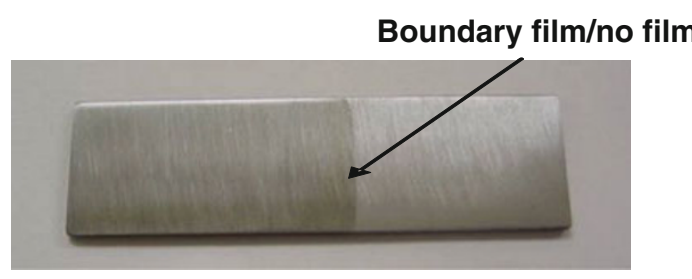

Fig. 2 Inhibitor film creates step on bare substrate

where the film has either become thinner than $2 \mu \mathrm{m}$ or has been removed from the surface, the software shows the steel surface data captured for that location, thus providing a realistic view of the film. Another feature of the tool allows for the creation of a histogram (height distribution) from the thickness values representing every pixel of the image (data set). The histograms are useful in analyzing film uniformity.

\section{Results}

The corrosion inhibitor results presented in this paper are for a standard oil-soluble corrosion inhibitor consisting of a conventional imidazoline-based corrosion inhibitor [CIA (CRW9229)] and a new water-soluble fatty acid/amidoamine corrosion inhibitor [CIB (CGO9051U)]. The actives in the two corrosion inhibitors are the same, but surfactant/ solvent packages are different. The results of WB corrosion tests, i.e. film persistency test obtained at $350{ }^{\circ} \mathrm{F}\left(177^{\circ} \mathrm{C}\right)$ and 100 psi (687 $\mathrm{kPa}) \mathrm{CO}_{2}$ are shown in Table 2. Coupons in these tests were filmed at concentrations of 2,500 and 5,000 ppm before being introduced into the WBs.

In this test, the water-soluble corrosion inhibitor (CIB) has better performance than the oil-soluble corrosion inhibitor (CIA) at same concentrations.

Optical profiling was used to determine the potential film thickness differences between CIB and CIA. This method was used to compare film thicknesses obtained with CIA and CIB after filming the coupons for a period of $10 \mathrm{~s}$ and drying for $10 \mathrm{~min}$ in neat corrosion inhibitors. The results obtained are shown in Fig. 4.
Table 2 Film persistency WB test of CIA and CIB

\begin{tabular}{lccc}
\hline Inhibitor & Concentration (ppm) & Corrosion rate (mpy) & \% Protection \\
\hline Blank & 0 & 109.2 & 0 \\
CIA & 2,500 & 4.3 & 96.1 \\
CIA & 5,000 & 3.9 & 96.4 \\
CIB & 2,500 & 1.9 & 98.2 \\
CIB & 5,000 & 1.1 & 98.9
\end{tabular}

Brine/oil ratio $=90 / 10,100 \mathrm{psi}(687 \mathrm{kPa}) \mathrm{CO}_{2}, 350{ }^{\circ} \mathrm{F}\left(177^{\circ} \mathrm{C}\right)$, 16-h test

The results indicate a thicker film of $3.9 \mu \mathrm{m}$ with the oilsoluble corrosion inhibitor CIA and $1.9 \mu \mathrm{m}$ with the waterdispersible corrosion inhibitor CIB.

After filming, the coupons were placed in a 24-h WB test at $25{ }^{\circ} \mathrm{C}$ with $1,662 \mathrm{kPa} \mathrm{CO}$. The surfaces that corroded were evaluated using the copper displacement method. The images of the coupons after using the copper displacement test are shown in Fig. 5.

The images in Fig. 5 show that treatments with CIB better protect the coupon than CIA in the WB test using coupons filmed from neat corrosion inhibitor solutions. CIB is dramatically superior to CIA. This contrasts with the tests where the coupon is filmed from a brine containing concentrated corrosion inhibitor. The film thickness after the WB test is then measured. For the coupon treated with CIA, there was no corrosion inhibitor left, so one was unable to make a measurement of its thickness. The film thickness of the coupons treated with CIB as determined using the optical profiler is shown in Fig. 6.

It will be noticed that the corrosion inhibitor film of the coupon filmed with CIB has increased from 1.9 to $3.2 \mu \mathrm{m}$, while the thickness of the coupon filmed with CIA is not seen after the test. Clearly, for the given conditions where both coupons are filmed in neat corrosion inhibitor (i.e. batch application), the water-based corrosion inhibitor CIB provided better protection than the oil-based corrosion inhibitor CIA. This is an interesting observation as before the test one would have thought that the coupon with the thicker corrosion inhibitor film would provide better protection.
Fig. 3 Fringes from a film thickness measurement. a Top of the film fringes; $\mathbf{b}$ film-metal interface fringes
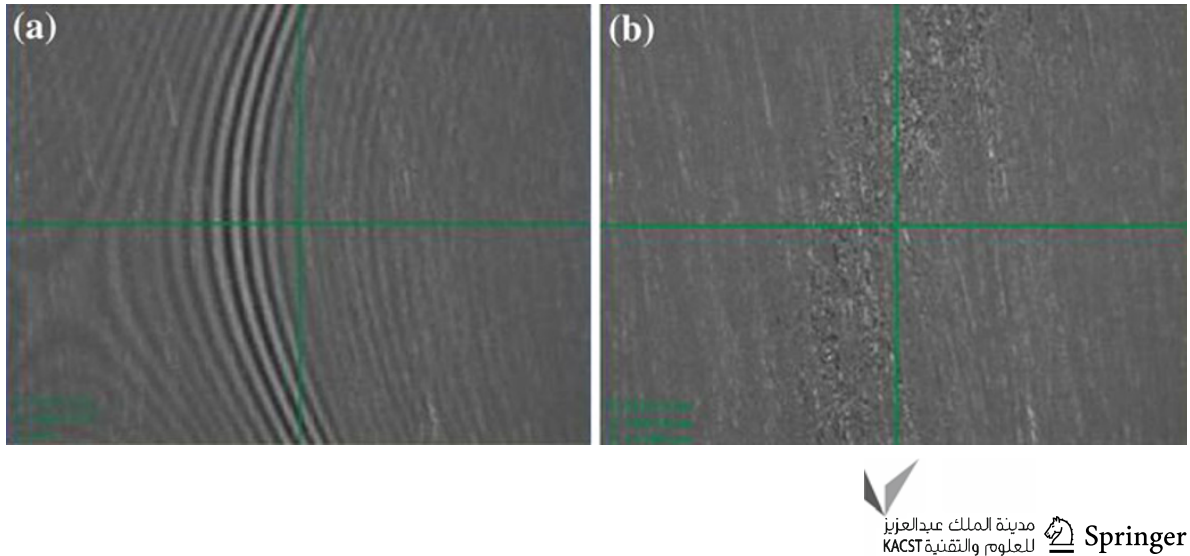
Fig. 4 Optical profiler results of film thickness using neat CIA and CIB
Fig. 5 Images of coupons treated with corrosion inhibitors CIA and CIB after the 24-h wheel test and the copper displacement test
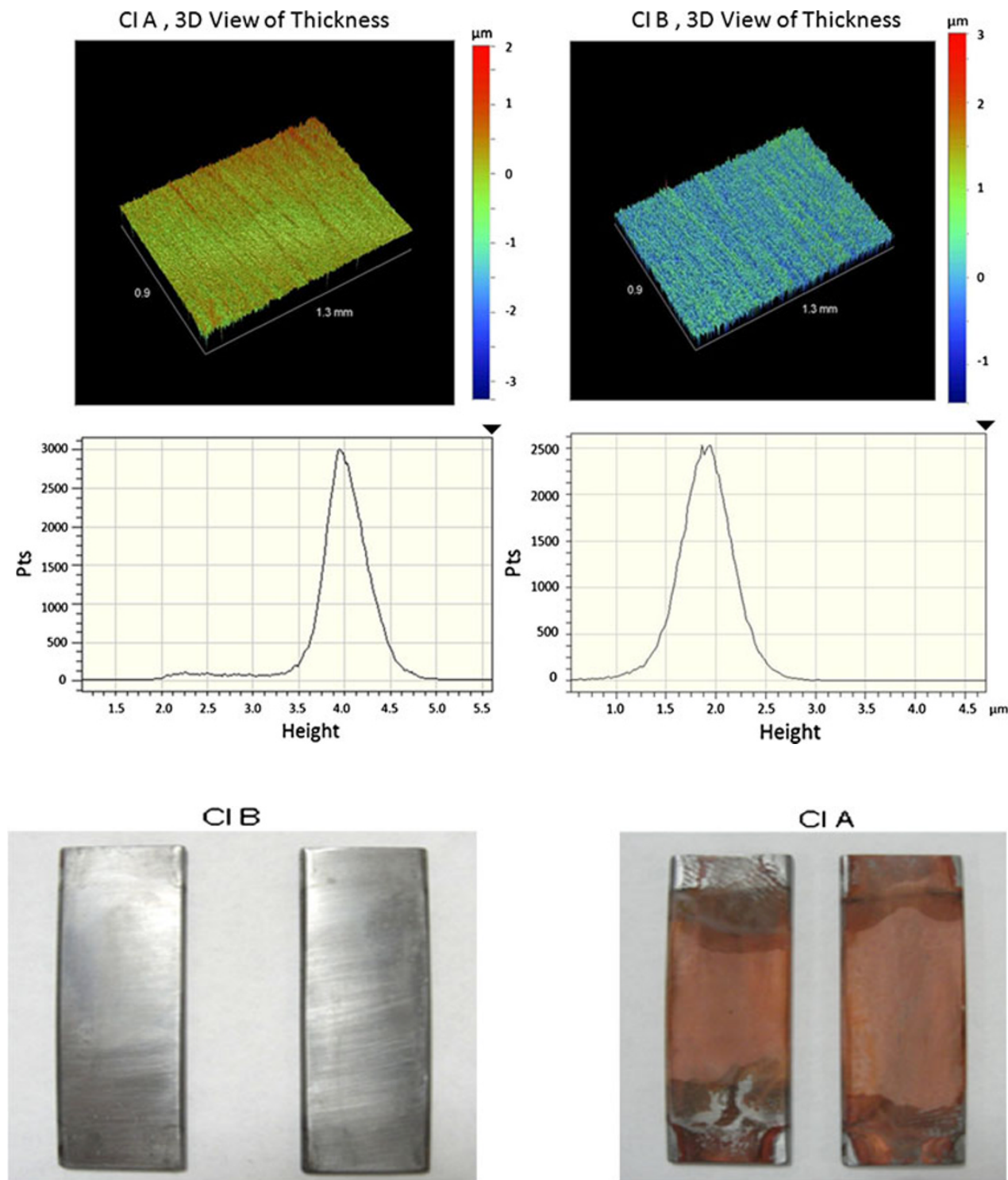

$\mathrm{Cl} \mathrm{A}$

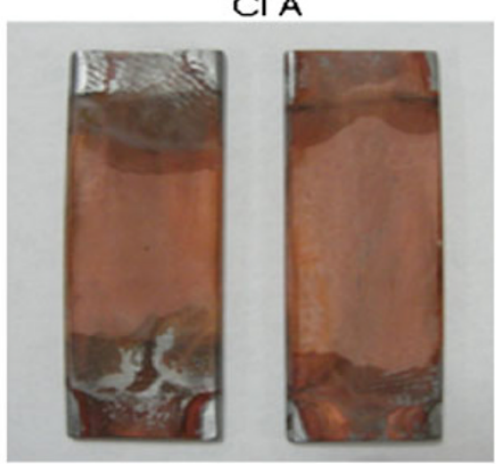

Images after u sing Copper Displacement Meth od
In previous work (Yang et al. 2007), it was found in field tests that a batch treatment of three gallons of water-dispersible corrosion inhibitor [CID (CRW9196)] was as effective as five gallons of a similar oil-soluble corrosion inhibitor [CIC (CRO193)]. This was a surprising result that was attributed to the fact that the oil-soluble corrosion inhibitor produced large spherical emulsion droplets of approximately $100 \mu \mathrm{m}$ in diameter, while the water-dispersible corrosion inhibitor had much smaller droplets (1-2 $\mu \mathrm{m})$. Due to the difference in size, the water-dispersible corrosion inhibitor can have $10^{5}-10^{6}$ more droplets dispersed in the brine. This likely improves the batch treatment performance.

The differences in oil-soluble corrosion inhibitor (CIC) and water-soluble corrosion inhibitor (CID) were studied using the optical profile method. Coupons were filmed in neat corrosion after filming for $10 \mathrm{~s}$ and drying for $10 \mathrm{~min}$. The coupons were then placed in a WB test at $220^{\circ} \mathrm{F}$ $\left(104{ }^{\circ} \mathrm{C}\right)$ and $15 \mathrm{psi} \mathrm{CO}_{2}(104 \mathrm{kPa})$. The results of the copper displacement are shown in Fig. 7.

Both coupons were protected; the optical profiler was used to measure the film thickness of the coupons after the test. These results are shown in Fig. 8.

The results provided in Fig. 8 appear to show that a more uniform and thicker film is obtained using the water-dispersible corrosion inhibitor CID $(6.7 \mu \mathrm{m})$ than the less uniform film obtained with the oil-soluble corrosion inhibitor CIC that has a film thickness varying between $3.9 \mu \mathrm{m}$ to $5.7 \mu \mathrm{m}$. The results obtained from the 24-hour wheel test and the optical profiler measurements of the representative film thickness are summarized in Table 3 . 


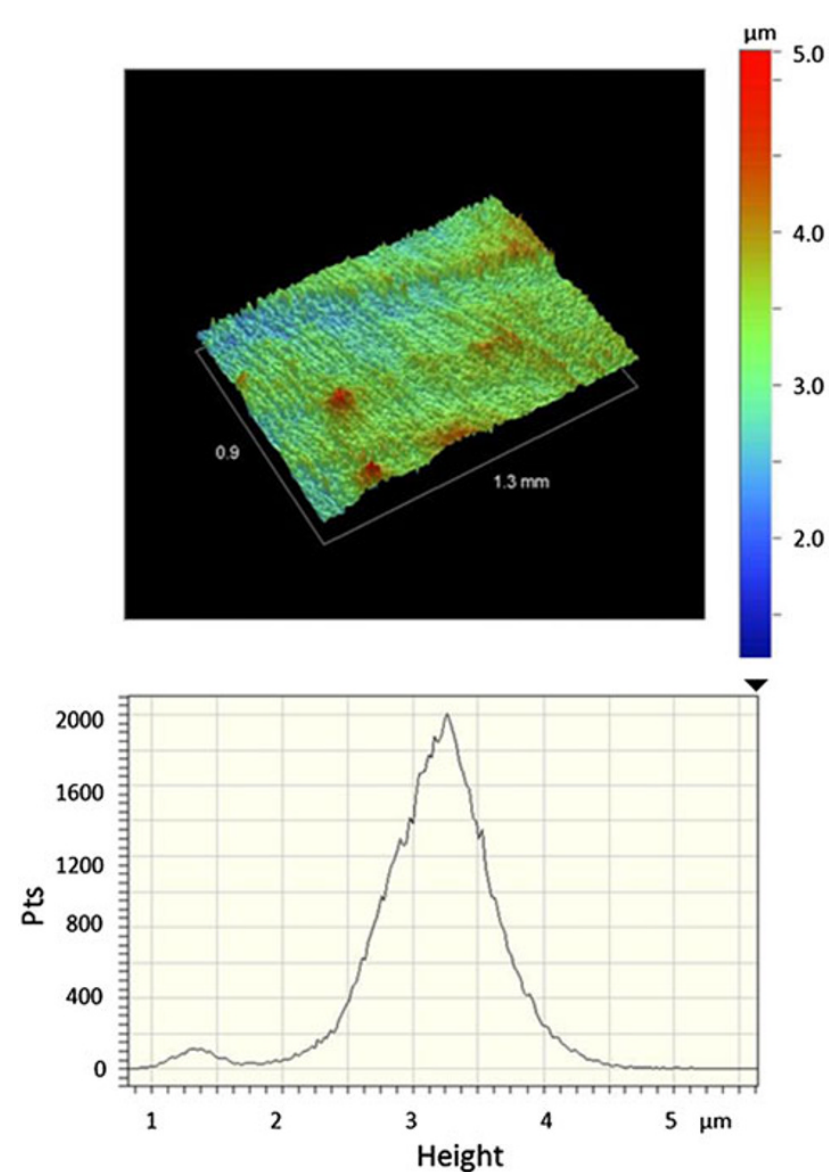

Fig. 6 Film thickness of coupons treated with CIB after 24-h wheel test

It can be seen from the results that the water-soluble corrosion inhibitor (CID) has a thicker and more uniform film after the test than the oil-soluble corrosion inhibitor (CIC). This likely results in the increased film persistence of the product as is seen in field tests (Yang et al. 2007).

\section{Discussion}

In previous work, it was found that a new water-dispersible corrosion inhibitor had better film persistency than the equivalent oil-based corrosion inhibitor (Yang et al. 2007). Oil-soluble corrosion inhibitors have been developed and used in HT gas wells. In previous work, we have documented the performance of oil-soluble corrosion inhibitor CIA in extremely challenging laboratory corrosion tests where the partial pressure of carbon dioxide was $10.3 \mathrm{MPa}$ $\left(1,500 \mathrm{psi} \mathrm{CO}_{2}\right)$ and the partial pressure of hydrogen sulfide $\left(\mathrm{H}_{2} \mathrm{~S}\right)$ was $0.0021 \mathrm{MPa}\left(3 \mathrm{psi} \mathrm{H}_{2} \mathrm{~S}\right)$ with rotation rates of $2,000 \mathrm{rpm}$ in an 80/20 mixture of brine and condensate (Ramachandran et al. 2006). Oil-soluble corrosion inhibitor CIA has been used in a variety of HT systems. In our earlier work, we documented its successful performance in different wells in systems with high bottom hole temperatures, high partial pressures of carbon dioxide, and some hydrogen sulfide and brines of different salinities (Ramachandran et al. 2006). CIA has been used frequently in batch treatments of deep HT wells.

A new water-dispersible, HT corrosion inhibitor CIB was developed that had similar HT stability and corrosion inhibitor properties as CIA (Ramachandran et al. 2009). Optical profiling is a technique used to determine the threedimensional profile of objects in a non-invasive manner. This method has been extended to measure the thickness of semitransparent batch inhibitor films (Menendez et al. 2010).

The resolution of the technique is in the micron range, so it does not cover the nanometer-thick monolayer or bi-layer corrosion inhibitor films that may exist. The results here show a thinner film with the water-based corrosion inhibitor (CIB) than the oil-based corrosion inhibitor (CIA) after filming in neat solution. After placing the filmed coupons in a $\mathrm{WB}$, we see better protection with the waterbased corrosion inhibitor (CIB) than the oil-based corrosion inhibitor (CIA). The film thickness of the coupon filmed with CIB also grows thicker from 1.9 to $3.2 \mu \mathrm{m}$ after being placed in the WB corrosion test. This may indicate that the film incorporates oil in the inhibitor film.

In the work characterizing corrosion inhibitors CIC and CID of earlier work (Yang et al. 2007), the new waterbased corrosion inhibitor (CID) has a thicker and more uniform film than the oil-based corrosion inhibitor (CID) after the 24-h wheel test. This may explain the greater film
Fig. 7 Images after copper displacement
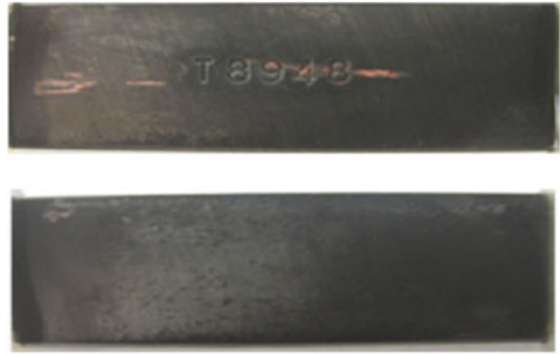

$\mathrm{ClO}$
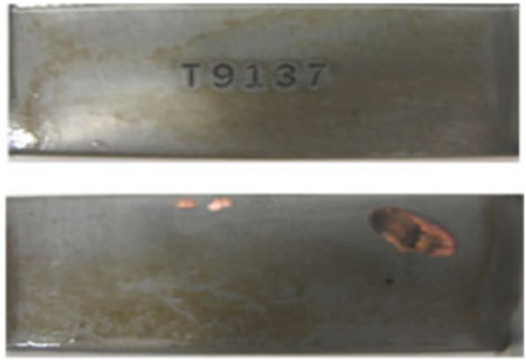

CI D

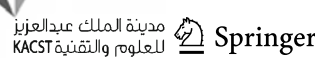


Fig. 8 Optical profiler results of film thickness using CIC and CID

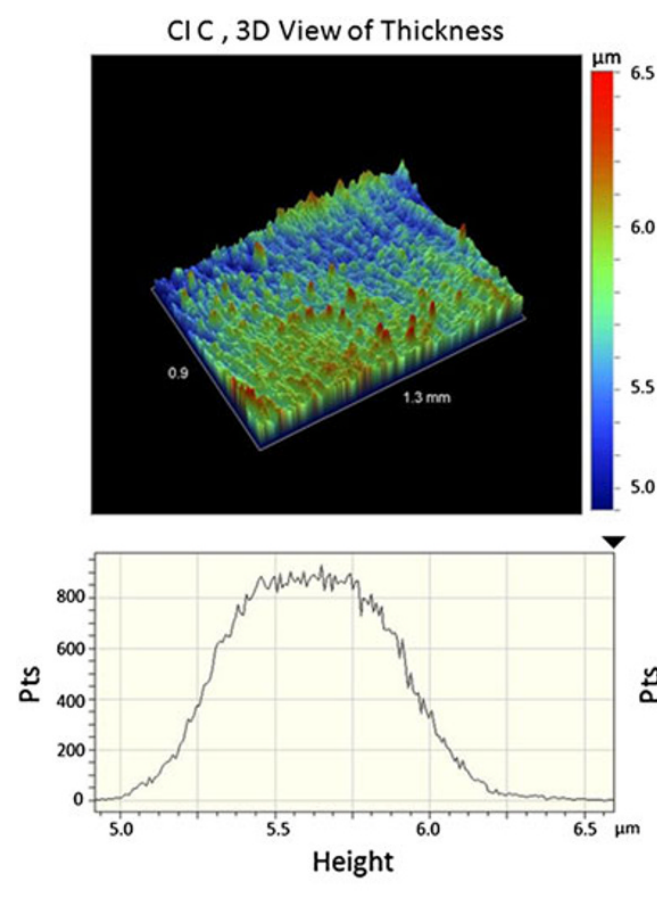

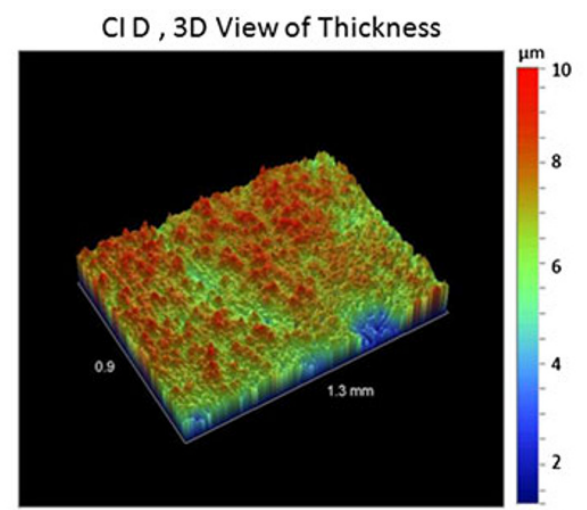

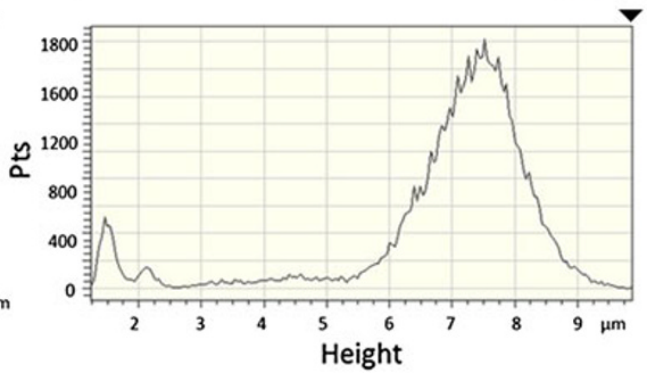

Table 3 Results of WB test and WLI film thickness for CIC and CID

\begin{tabular}{lccl}
\hline Inhibitor & Corrosion rate (mpy) & \% Protection & Film thickness $(\mu \mathrm{m})$ \\
\hline Blank & 42.6 & 0 & \\
CIC & 3.9 & 90.8 & $2.7 \pm 0.6$ \\
CID & 4.0 & 90.6 & $3.3 \pm 0.4$ \\
\hline
\end{tabular}

persistency of the water-based corrosion inhibitor (CID) than the oil-based corrosion inhibitor (CIC) seen in the field (Yang et al. 2007).

\section{Conclusion}

An oil-soluble corrosion inhibitor CIA has been used in a variety of HT systems (Ramachandran et al. 2006). A new water-dispersible, HT corrosion inhibitor CIB was developed that had similar HT stability and corrosion inhibitor properties as CIA. Optical profiling was used to compare the film thickness and uniformity of oil-based and waterbased corrosion inhibitors that work in applications as high as $204{ }^{\circ} \mathrm{C}$. The water-soluble corrosion inhibitor (CIB) had a thinner film $(1.9 \mu \mathrm{m})$ than the oil-soluble corrosion inhibitor (CIA) $(3.9 \mu \mathrm{m})$ immediately after the filming test in neat corrosion inhibitor. After a 24-h WB test, however, it was seen that this thinner film was better able to protect the coupon after exposure to a WB test and the film grew to a thickness of $3.2 \mu \mathrm{m}$.

The optical profiler was also used to compare the oilsoluble corrosion inhibitor (CIC) and water-based corrosion inhibitor (CID) studied earlier by Yang et al. (2007). It was found in this work that the water-dispersible corrosion inhibitor (CID) had better film persistency than the equivalent oil-based corrosion inhibitor (CIC) in field tests. It was also found that the water-dispersible corrosion inhibitor (CID) has several orders of magnitude more droplets in brine. In our work, we have found that the water-dispersible corrosion inhibitor (CID) has a thicker and more uniform film $(6.7 \mu \mathrm{m})$ than the oil-based corrosion inhibitor (CIC) where the corrosion inhibitor film varies between 3.9 and $5.7 \mu \mathrm{m}$ after a $24-\mathrm{h}$ WB tests.

The results show that systems with a thicker, moreuniform intact corrosion inhibitor films after a performance test such as the WB test will be more film persistent than those systems that have thinner corrosion inhibitor films after the test.

Open Access This article is distributed under the terms of the Creative Commons Attribution License which permits any use, distribution, and reproduction in any medium, provided the original author(s) and the source are credited.

\section{References}

Goodfellow RB, Barr EE (2001) A case study of the design and operation of high $\mathrm{CO} 2$ production with $\mathrm{H}_{2} \mathrm{~S}$. In: Paper 01047 presented at CORROSION 2001, Houston, Texas, USA, 11-16 March

Jovancicevic V, Ramachandran S, Prince P (1998) Inhibition of $\mathrm{CO}_{2}$ corrosion by imidazolines and their precursors. In: Paper No. 98018 presented at CORROSION/98, San Diego, California, USA, 22-27 March 
Menendez C, Bojes J, Lerbscher J (2010) Obtaining batch corrosion inhibitor film thickness measurements using an optical profiler. In: Paper No. 10272, presented at CORROSION 2010, San Antonio, Texas, USA, 14-18 March

Place MC Jr (1992) Corrosion inhibition for severely corrosive gas wells. Corrosion 48:341-352

Ramachandran S, Jovancicevic V (1998) Molecular modeling of the inhibition of mild steel $\mathrm{CO}_{2}$ corrosion by imidazolines. In: Paper No. 98017 presented at CORROSION/98, San Diego, California, USA, 22-27 March

Ramachandran S, Tsai BL, Blanco M, Chen HJ, Tang Y, Goddard WA (1996) Self-assembled monolayer mechanism for corrosion inhibition of iron by imidazolines. Langmuir 12:6419-6428

Ramachandran S, Ahn YS, Greaves MV, Jovancicevic V, Bassett J (2006) Development of High temperature, high pressure corrosion inhibitor. In: Paper No. 06337 presented at CORROSION 2006, San Diego, California, USA, 12-16 March

Ramachandran S, Jovancicevic V, Long J (2009) Development of a new water soluble corrosion inhibitor. In: Paper No. 09237 presented at CORROSION 2009, Atlanta, Georgia, USA, 22-26 March

Smith FG (1982) Controlling corrosion in Deep South Louisiana gas wells. World Oil 195:77-79

Yang J, Jovancicevic V (2009) US Patent 7,615,516

Yang J, Jovancicevic V, Mancuso S, Mitchell J (2007) High performance batch treating corrosion inhibitor. In: Paper 07693 presented at CORROSION 2007, Nashville, Tennessee, USA, 11-15 March

Zeringue R (2006) Ultra-HPHT conditions will be the next challenge. Oil Gas J 104:47-51 